\title{
Survey of Mycotoxigenic Fungi in Concentrated Poultry Feed in Niger State, Nigeria
}

\author{
Adeniran Lateef Ariyo ${ }^{1}$, Makun Hussaini Anthony ${ }^{2} \&$ Muhammad Hadiza Lami ${ }^{2}$ \\ 1 Department of Physiology and Biochemistry, Faculty of Veterinary Medicine, University of Abuja, Abuja, \\ Nigeria \\ ${ }^{2}$ Department of Biochemistry, Federal University of Technology, Minna, Nigeria \\ Correspondence: Adeniran Lateef Ariyo, Department of Physiology and Biochemistry, Faculty of Veterinary \\ Medicine, University of Abuja, PMB 117, Abuja, Nigeria. E-mail: apolloadeniran@yahoo.com
}

Received: July 8, 2012 Accepted: March 2, 2013 Online Published: March 27, 2013

doi:10.5539/jfr.v2n2p128 URL: http://dx.doi.org/10.5539/jfr.v2n2p128

\begin{abstract}
In Nigeria, concentrated poultry feed is a vital component of animal production and health but there was no reliable mycogram in Niger state, Nigeria. As a result this study determined the incidence of mycotoxigenic fungi in both commercial and privately milled concentrated poultry feeds. A total of 100 poultry feed samples consisting of 52 privately milled poultry feed and 48 commercial feed samples were collected. Mycoflora in the feed was determined. Nine fungi genera were isolated. The most frequently isolated fungi genera in both privately milled and commercial feed was Aspergillus spp which was about $40 \%$ of mould isolate. Penicillium spp is $20 \%$ in private feed and $13 \%$ in commercial feed. A total of 874 fungi were isolated consisting of 458 fungi species in privately milled feed and 416 fungi species found in commercial feed. Mycotoxigenic fungi genera, Aspergillus, Penicillium, Fusarium and Alternaria were isolated. Aspergillus flavus is the commonest isolated fungi species.
\end{abstract}

Keywords: poultry feed, fungi, mycological survey, commercial

\section{Introduction}

Worldwide fungi contamination of food and feedstuff has become a source of concern. Fungi are well adapted for growth and development over surfaces and through solid materials (Moss, 1992). The hyphae of some fungi are capable of penetrating hard surfaces (Gow et al., 2002). This group of microorganisms are ubiquitous in nature (Park et al., 2005), and are mostly saprophytes that breakdown and transport the available nutrients to the actively growing hyphae (Smith \& Moss, 1985). Or they may be parasites (Moss, 1992) by invading and exhibiting their pathogenic potentials on both plant and animal species (Parker \& Gilbert, 2004). Forages and cereals are often contaminated by fungi in the field, or during processing, transportation and storage when conditions such as temperature and relative humidity are favourable. Temperature and relative humidity of above $30^{\circ} \mathrm{C}$ and $80-100 \%$ respectively are favourable for fungal growth (Blaha et al., 1990). Other conditions include nutrient availability (Njobeh, 2003) and oxygen supply (Filtenborg et al., 2000). Most of the fungi invade only a minor fraction of feed particles with appropriate condition for their growth.

The presence of visible mould spores may not likely serve as a reliable guide to mycotoxin content (Smith \& Seddon, 1998) but must not be disregarded when assessing the occurrence of mycotoxins. This is because it provides a foundation for evaluation of risk of mycotoxin contamination. Observations of fungi in food and animal feed are likely indications of the presence of mycotoxins and it is only through the cultivation of fungi under laboratory conditions when the presence or absence of fungi can be appreciated.

Pathogenic micro organisms and their secondary metabolites (mycotoxins) in general chain of nutrition represent the most important potential risk to animal and human health. Because of the harmful effect of mycotoxins in chain of nutrition of humans and animals, in this paper, presence of potentially mycotoxigenic fungi in samples of poultry feed was determined. 


\section{Materials and Methods}

\subsection{Collection of Samples}

100 poultry feed samples were collected between February and March 2011 from different poultry farms in Minna, Niger state, which is a state in the North western part of Nigeria and the largest state in the country, a state with favourable climate (average annual temperature of $31.7^{\circ} \mathrm{C}$ and average humidity of $51.6 \%$ ) and it is hot and humid for most part of the year especially between May and October $\left(29.5^{\circ} \mathrm{C}\right.$ and $\left.73.1 \%\right)$ which is conducive for fungal growth and mycotoxin production on food. The microclimatic environment is dry at the time of sample collection. The annual rainfall in Niger state is between 1000-1200 mm.

52 samples from privately milled poultry feed were collected from six different farms and 48 samples from six commercial poultry feed brands were also taken from different farms using commercial feed. These samples were taken before the feed was served to birds. The samples were labeled based on the manufacturer as commercial feeds or privately milled feeds. The commercial feeds were labeled according to their different brands and the private feed labeled with the farms' name. About 200 grams of the feed were taken and packaged in well labeled paper bags and immediately taken to the laboratory for fungi isolation and identification.

\subsection{Isolation and Identification of Fungi}

Fungi were isolated and cultured according to the method described by Pitt and Hocking (1997). About $1 \mathrm{~g}$ of the ground grain was diluted in $9 \mathrm{ml}$ of sterile distilled water which was followed by five other serial dilutions. One millitre of the extract was placed at random in each of the Petri-dishes containing potato dextrose agar (PDA) and chloramphenicol (500 mg per litre). The pure culture was used for identification between five and seven days of incubation. Determination of each species of fungi was done using the keys of Klich and Pitt (1988) and Klich (2002) for Aspergillus spp. Nelson et al. (1983) for Fusarium spp. and Pitt and Hocking (1997) for Penicillium and other genera. This is done by observing both microscopic characteristics of the colonies on various media used as well as the microscopic morphology and measurement of the candidiophores (after staining mycelia with $0.1 \%$ fucshin dissolved in lactic acid) under microscope. The pure culture of different isolate (identified fungi) were aseptically sub-cultured in potatoes dextrose agar slant and incubated.

Identification of isolates was carried out at the Microbiology laboratory of Federal University of Technology, Minna and Microbiology Department, Faculty of Veterinary Medicine, University of Abuja.

\section{Result and Discussion}

In this survey nine fungi general were isolated as the natural contaminant of both commercial and private feeds milled in Minna Niger state. The fungi genera includes Aspergillus, Penicillium Fusarium, Mucor, Rhizopus, Cladosporum, Alternaria, and Torula. This result is similar to those published by (Makun et al., 2010; Atehnkeng et al., 2008; Kpodo et al., 2010) as the contaminant of cereal crops which are the ingredient used in poultry feed production.

Table 1 showed the frequency of isolated fungi genera in both private and commercial poultry feed samples, where a significant difference was obtained $\left(\mathrm{X}^{2}=199.818 ; \mathrm{P}<0.05\right.$ and $\left.\mathrm{X}^{2}=237.053 ; \mathrm{P}<0.05\right)$ respectively, being the genus Aspergillus and Penicillium the most frequently isolated. This result is similar to the ones obtained by Rosa et al. (2006), Oliveira et al. (2006) and Figueroa et al. (2009), who found that Aspergillus and Penicillium were the most frequently isolated genera in the poultry feed samples analyzed. Aspergillus has been shown to be predominant in cereals and other ingredients used in producing poultry feeds in the tropics as in the case of Nigeria (Pitt \& Hocking, 1997; Makun et al., 2009). A total of 456 species of fungi were isolated in private milled feed and 416 fungi commercial poultry feeds. Table 2 shows that Aspergillus spp has the highest frequency of occurrence and Torula spp is the least fungi isolated. Aspergillus and penicillium are frequently isolated are the commonest and widespread in nature, and have been shown as fungal contamination of African foods and feeds (Atehnkeng et al., 2008; Essono et al., 2009; Njobeh et al., 2009; Makun et al., 2010). 
Table 1. Occurrence and frequency of fungi genera isolated from privately milled and commercial poultry feed

\begin{tabular}{|c|c|c|c|c|}
\hline \multirow[b]{2}{*}{ Genera } & \multicolumn{2}{|c|}{ Private feed } & \multicolumn{2}{|c|}{ Commercial feed } \\
\hline & Incidence & Frequency $(\%)$ & Incidence & Frequency $(\%)$ \\
\hline Alternaria & 11 & 2 & 8 & 2 \\
\hline Aspergillius & 189 & 41 & 167 & 40 \\
\hline Cladosporum & 19 & 4 & 20 & 5 \\
\hline Fusarium & 31 & 7 & 47 & 11 \\
\hline Mucor & 54 & 12 & 65 & 16 \\
\hline Penicillum & 91 & 20 & 54 & 13 \\
\hline Rhizopus & 51 & 11 & 45 & 11 \\
\hline Torula & 1 & 0.2 & 3 & 1 \\
\hline Yeast & 9 & 2 & 7 & 2 \\
\hline
\end{tabular}

Private feed: $* * * X 2=199.818$ Highly significant at $\mathrm{P}<0.05$;

Commercial feed: $* * * X 2=273.053$ highly significant at $\mathrm{P}<0.05$.

Table 2. Occurrence and frequency of fungi species isolated from privately milled and commercial poultry feed

\begin{tabular}{|c|c|c|c|c|}
\hline \multirow[b]{2}{*}{ Fungi Spp } & \multicolumn{2}{|c|}{ Private Milled Feeds } & \multicolumn{2}{|c|}{ Commercial Feeds } \\
\hline & Incidence & Frequency (\%) & Incidence & Frequency (\%) \\
\hline Alternaria spp & 6 & 1 & 5 & 1 \\
\hline Aspergillius flavus & 43 & 9 & 47 & 11 \\
\hline A.fumigatus & 29 & 6 & 21 & 5 \\
\hline A.malleus & 11 & 2 & 8 & 1 \\
\hline A. nidulans & 4 & 1 & 5 & 1 \\
\hline A. niger & 41 & 9 & 33 & 7 \\
\hline A.ochraceus & 19 & 4 & 6 & 1 \\
\hline A. parasiticus & 32 & 7 & 34 & 8 \\
\hline A. flaviceps & 10 & 2 & 13 & 3 \\
\hline Cladosporum spp & 11 & 2 & 14 & 3 \\
\hline Curvularia spp & 8 & 1 & 6 & 1 \\
\hline Fusarium spp & 19 & 4 & 29 & 6 \\
\hline F. oxysporum & 5 & 1 & 7 & 2 \\
\hline F.semitectum & 2 & 0.4 & 5 & 1 \\
\hline F.solani & 5 & 1 & 6 & 1 \\
\hline Mucor spp & 54 & 11 & 65 & 15 \\
\hline Penicillium spp & 46 & 10 & 33 & 7 \\
\hline P. citrinum & 7 & 1 & 5 & 1 \\
\hline P. notatum & 8 & 1 & 2 & 0.4 \\
\hline P. rubrum & 8 & 1 & 6 & 1 \\
\hline P.verrucosum & 22 & 4 & 8 & 1 \\
\hline Rhizopus spp & 15 & 11 & 45 & 10 \\
\hline Torula spp & 1 & 0.2 & 3 & 1 \\
\hline Yeast & 9 & 1 & 7 & 1 \\
\hline
\end{tabular}




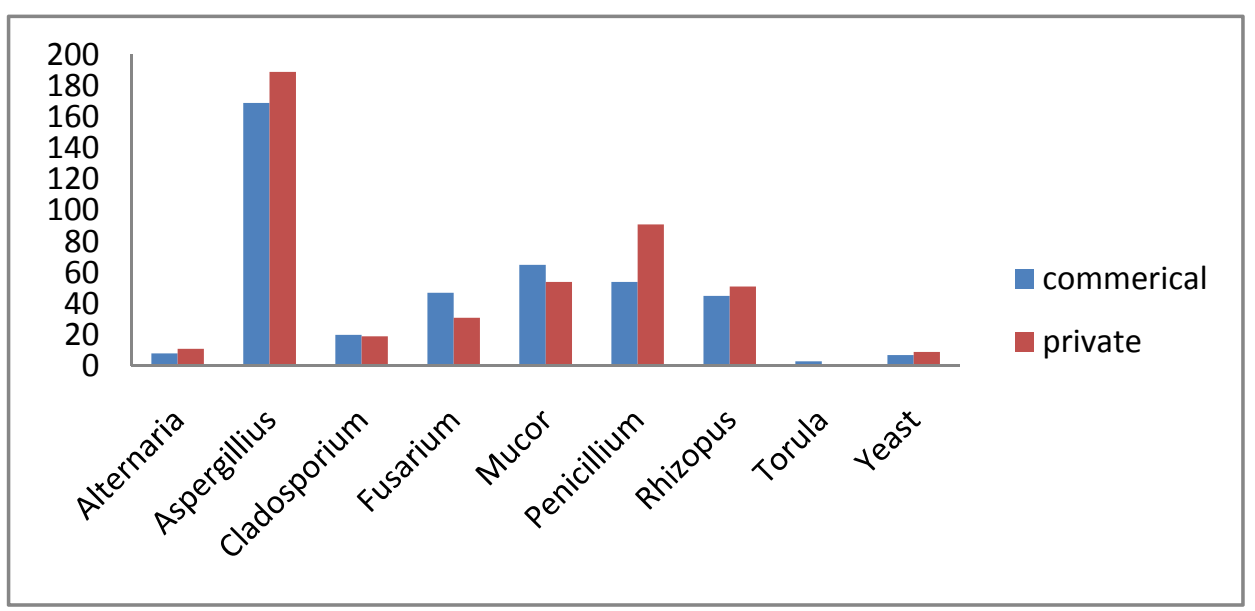

Figure 1. Frequency of fungi general isolated from private and commercial feed

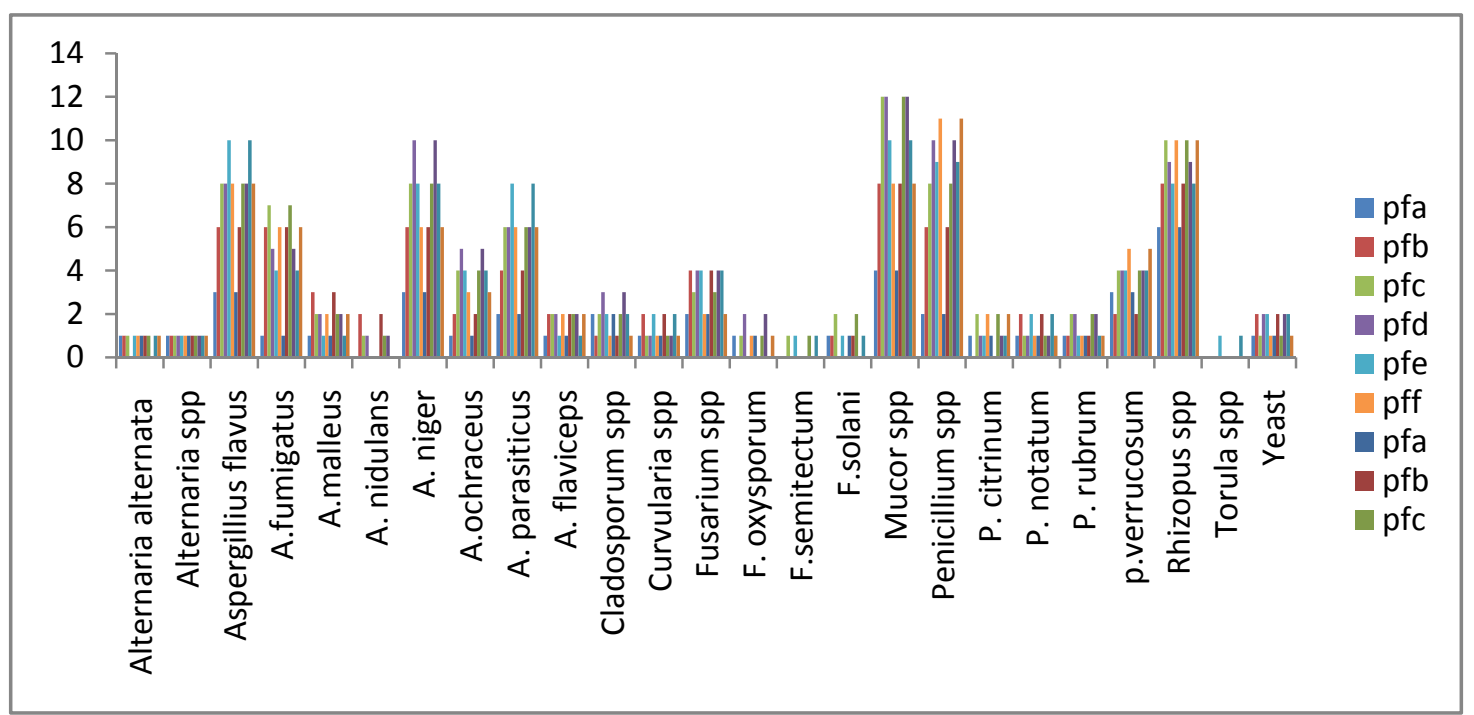

Figure 2. Frequency of fungi species isolated from private feed

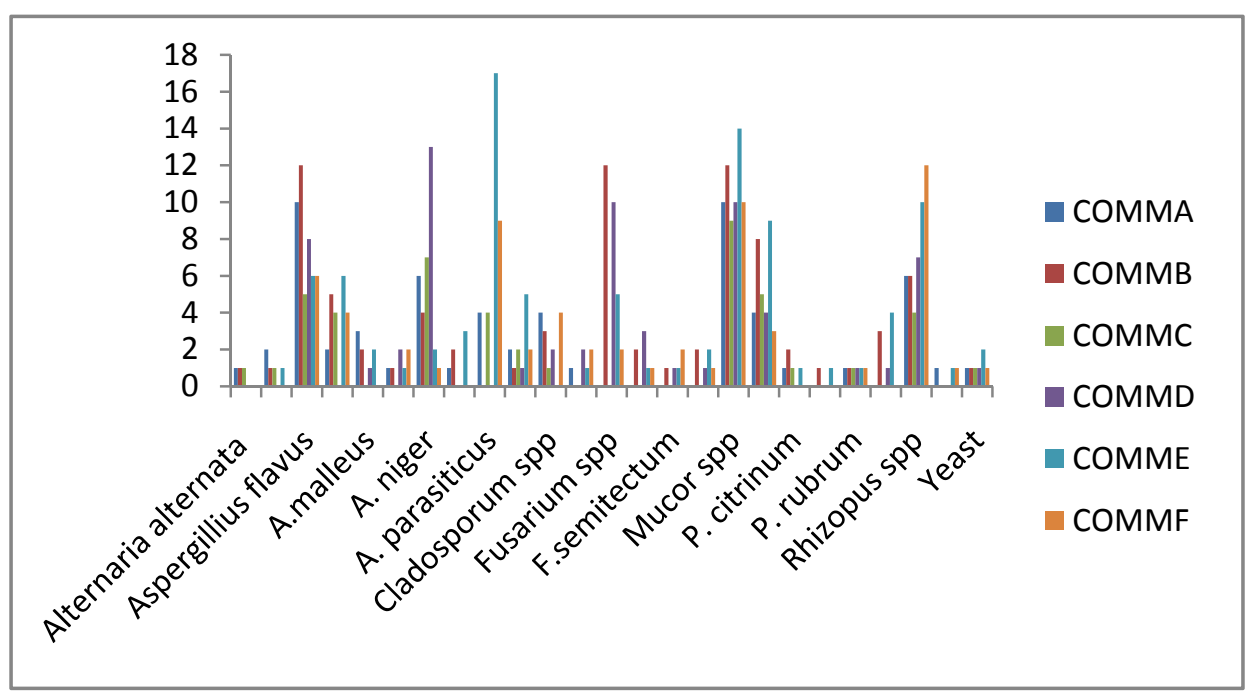

Figure 3. Frequency of fungi species isolated from commercial feed 
Aspergillus flavus is the most isolated species in this work both in private and commercial poultry feed. Aspergillus flavus was the most isolated species in poultry feeds in different countries (Rosa et al., 2006; Figueroa et al., 2009). A. flavus produces mycotoxin like aflatoxin, kojic acid, aspergillic acid and cyclopiazonoid acid (FAO, 2003). Aflatoxin B1 is carcinogenic to human (IARC, 1993), in chickens, aflatoxin increased susceptibility to, or severity of ceacal coccidiosis, Marek's disease (Edds, 1976), salmonellosis (Smith et al., 1969; Wyatt \& Hamilton, 1975), inclusion body hepatitis (Singh et al., 1996), and infectious bursal disease virus (Chang \& Hamilton, 1982; Somvanshi \& Mohanty, 1991). Vaccination failures were linked to aflatoxicosis in chickens (Anjum, 1994; Pruthi et al., 1992), and impaired response to vaccination responses was demonstrated for Newcastle disease, infectious bronchitis, infectious bursal disease, and fowl cholera (Azzam \& Gabal, 1997; Azzam \& Gabal, 1998; Bunaciu et al., 1998).

A. niger is higher in private milled poultry feed than the commercial feed because the commercial feed manufacturer uses cotton seed as their ingredient compared to private feed which used maize or corn sources from local market as their ingredient. A. niger and A. ochraceus has a great capacity to produce Ochratoxin A (OTA) (Dalcero et al., 1998; Rosa et al., 2006). A. ochraceus is capable of producing high amount of secondary toxic metabolites such as Ochratoxin A, penicillin acid, Xantomegnin, Viomellein and Vioxantin. Effect of OTA in poultry include delay of sexual maturity in pullets, reduction in mean body weight, decrease in egg weight and reduced egg production, immunosupression, impaired vaccination response (Kozaczynski, 1994; Politis et al., 2005). OTA also has sensitive effect on the kidney and liver. Rosa et al. (2006) was able to demonstrate that 9 strain out of the 74 strains found of $A$. ochraceus in bird feeds in Brazil were capable of producing OTA in concentration of between 53 and $116 \mathrm{ug} / \mathrm{kg}$.

Aspergillus fumigatus causes a condition called aspergillosis which is an infectious, non contagious respiratory disease affecting birds characterized by gasping, sleepiness, loss of appetite and sometimes convulsion and death. Occasionally the organism invades the brain, causing paralysis or other forms of nervous symptoms. Aspergillus, penicillium and fusarium are toxigenic fungi; they produce very important mycotoxins like Ochratoxin, aflatoxin, fumonism and trichothecene.

High level of Mucor spp and Rhizopus spp was a result of these feed ingredient which are higher in Carbohydrate in Nature. The high incidence of Mucor spp and Rhizopus spp is in conformity with the Infeanyi et al. (2007) which showed a high frequency of these fungi in poultry feed ingredients. Mucor and Cladosporun species may cause mycotic abortion and allergy in animal and human as a result of systemic and respiratory transmission respectively (Rippon, 1988).

The mycotoxigenic fungi general identified in this research were Aspergillus, Fusarium, Alternaria and Penicillium.

Controlling mould growth and mycotoxin production is very important to the feed manufacturer and livestock producer. Control of mould growth in feeds can be accomplished by keeping moisture low, feed fresh, and equipment clean and using mould binders and inhibitors. Grains and other dry feedstuffs should be stored at a moisture level of less than 14 percent to prevent mould growth.

Aeration of grain bins is important to reduce moisture migration and keep the feedstuff dry (Jones et al., 1994).

The use of chemical mould inhibitors is a well establish practice in the feed industry. However, mould inhibitors are only one of several tools useful in the complex process of controlling the growth of moulds, and they should not be relied upon exclusively.

\section{Conclusion and Recommendation}

It is important to note that the impact of mycotoxigenic fungi on animals extend beyond the symptoms. The mycotoxin produced by the fungi poses a serious economic impact worldwide. The economic impact result from lowered productivity, reduced feed conversion efficiency which causes reduced weight gain, less meat and egg production, increased disease incidence because of immunosupression, damage to organs in the body. Since there has not been a mycogram of poultry feed in Niger state, there is need to develop one using this mycological survey as a baseline data for further studies which will involve more local government areas under different microclimatic condition.

\section{Aknowlegdements}

I wish to acknowledge members of staff of Biochemistry, Microbiology Department, Federal University of Technology Minna, Niger state and Mr Akeem Onigbanjo of Mycology laboratory, Faculty of Veterinary Medicine University of Abuja for their technical assistance. 


\section{References}

Anjum, A. D. (1994). Outbreak of infectious bursal disease in vaccinated chickens due to aflatoxicosis. Indian Journal of Animal Science, 71, 322-324.

Atehnkeng, J., Ojiambo, P. S., Donner, M., Ikotun, T., Sikora, R. A., \& Cotty, P. J. (2008). Distribution and toxigenicity of Aspergillus species isolated from maize kernels from three agro-ecological zones in Nigeria, $\begin{array}{llllll}\text { International Journal of Food } & \text { Microbiology, } & \text { 122, } & \text { 74-84. }\end{array}$ http://dx.doi.org/10.1016/j.ijfoodmicro.2007.11.062

Azzam, A. H., \& Gabal, M. A. (1997). Interaction of aflatoxin in the feed and immunization against selected infectious diseases. Avian Pathology, 26, 317-325. http://dx.doi.org/10.1080/03079459708419214

Azzam, A. H., \& Gabal, M. A. (1998). Aflatoxin and immunity in layer hens. Avian Pathology, 27, 570-577. http://dx.doi.org/10.1080/03079459808419386

Bunaciu, P. R., Tudor, D. S., Cureu, I., \& Bunaciu, P. (1998). The effect of ascorbic acid in the decreasing of negative effects ofanatoxins in broilers. Proc European Poultry Conference, 10, 384-388.

Chang, C. F., \& Hamilton, P. B. (1982). Increased severity and new symptoms of infectious bursal disease during aflatoxicosis in broiler chickens. Poultry Science, 61, 1061-1068. http://dx.doi.org/10.3382/ps.0611061

Dalcero, A., Mangoli, C., Luna, M., Ancasi, G., Reysono, M. M., Chiaccheria, S., ... Palacio, G. (1991). Mycoflora and naturally occurring mycotoxin in poultry feeds in Argentina. Mycopathology, 141, 37-43. http://dx.doi.org/10.1023/A:1006868002985

Edds, G. T., \& Osuna, A. (1976). Aflatoxin BI increases infectious disease losses in food animals. USA Animal Health Association, 80, 434-441.

Essono, G., Ayodele, M., Akoa, A., Foko, J., Filtenborg, O., \& Olembo, S. (2009). Aflatoxin producing Aspergillus spp. and aflatoxin levels in stored cassava chips as affected by processing practice. Food Control, 20, 648-654. http://dx.doi.org/10.1016/j.foodcont.2008.09.018

FAO. (2003). Manual on the application of the HACCP system in mycotoxin prevention and control (1st ed.). Rome: Food and Agriculture Organisation of the United Nation.

Figueroa, S., Centeno, S., Calvo, M. A., Rengel, A., \& Adelantado, C. (2009). Mycobiodata and concentration of Ochratoxin A in concentrated poultry feed from Venezuela. Pakinstan Journal of Biological Sciences, 12(7), 589-594. http://dx.doi.org/10.3923/pjbs.2009.589.594

Filtenborg. O., Frisvad, T. C., \& Samson, R. A. (2000). Specific association of fungi in foods and influence of physical environmental factors. In R. A. Samson, E. S. Hoekstra, J. C. Frisvad, \& O. Filtenborg (Eds.), Introduction to Food-and Airborne Fungi (6th Ed., pp. 306-320). Utrecht: Centralbureau voor Schimmelculture.

Gow, N. A. R., Brown, A. J. P., \& Odds, F. C. (2002). Fungal morphogenesis and host invasion. Current Opinion in Microbiology, 5(4), 366-371. http://dx.doi.org/10.1016/S1369-5274(02)00338-7

Halfon-Meiri, A., \& Barki, G. (1990). Mycoflora involved in seed germ discolouration of popcorn and its effect on seed quality. Mycopathologia, 11, 37-41. http://dx.doi.org/10.1007/BF00442768

IARC. (1993). Iarc monographs on the evaluation of carcinogenic risks to humans: some naturally occurring substances, food items and constituents, heterocyclic aromatic amines and mycotoxins. Ochratoxin A. International Agency for Research on Cancer, 56, 26-32.

Infeanyi, C. O., Prince, I. O., Martin, C. U., Maxmal, N. O, Joy, O. O, Apeh, A. O., ... Vincent II. (2007). Assesment of the mycoflora of poultry feed raw materials in a Humid tropical environment. Journal of America Science, 3(1).

Jones, F. T., Genter, M. B., Hagler, W. M., Hansen, J. A., \& Mowrey, B. B. (1994). Understanding and coping with effects of mycotoxins in livestock feed and forage. North Carolina Cooperative Extension Services (p. 114). Carolina.

Klich, M. A. (2002). Introduction; economic and medical importance of Aspergillus. In Identification of common Aspergillus species (pp. 1-16). Centraalbureau voor Schimmelculture, Utrecht: The Netherlands (Publishers). 
Klich, M. A., \& Pitt, J. I. (1988). A Laboratory Guide to Common Aspergillus Species and Their Teleomorphs. North Ryde, N. S. W.: CSIRO Division of Food Research.

Kozaczynski, W. (1994). Experimental ochratoxicosis A in chickens. Histopathological and histochemical study. Archive of Veterinary Pathology, 34, 205-219.

Kpodo, K., Thrane, U., \& Hald, B. (2000). Fusaria and fumonisins in maize from Ghana and their co-occurrence with aflatoxins. International Journal of Food Microbiology, 61, 147-157. http://dx.doi.org/10.1016/S0168-1605(00)00370-6

Makun H. A., Gbodi, T. A. H., Akanya, O. H., Salako, E. A., \& Ogbadu, G. A. (2009). Fungi and Some Mycotoxins Found in Mouldy Sorghum in Niger State, Nigeria. World Journal of Agricultural Sciences, 5(1), 5-17.

Makun, H. A., Anjorin, S. T., Moronfoye, B., Adejo, F. O., Afolabi, O. A., Fagbayibo, G., ... Surajudeen, A. A. (2010). Fungal and aflatoxin contamination of some human food commodities in Nigeria. African Journal of Food Science, 4(4), 127-135.

Moss, M. O. (1992). Mycotoxic fungi. In: Microbial Food Poisoning. In A. R. Elley (Ed.), Chapman and Hall (pp 73-106). London, Glassgow, New York, Tokyo, Melbourne, Madras.

Mucor A. C. (1987). Origin and control of mycotoxin Kumin Europe N. V. milling flavor and feed magazine. Turret wheat.

Nelson, P. E., Toussoun, T. A., \& Marasas, W. F. O. (1983). Fusarium species an Illustrated Manual for Identification (p. 193). Pennsylvania: The Pennsylvania State University Press.

Njobeh, B. P., Dutton, M. F., Koch, S. H., \& Chuturgoon, A. (2009). Contamination with storage fungi of human foods. Cameroon International Journal of Food Microbiology, 135, 193-198. http://dx.doi.org/10.1016/j.ijfoodmicro.2009.08.001

Njobeh, P. B. (2003). Influence of composition and storage conditions on diet quality and productivity of broiler chickens (Master thesis). University of Natal, South Africa.

Oliveira, G., Ribeiro, J., Fraga, M., cavaglieri, L., Direito, G., ... Rosa, C. (2006). Mycobiodata in poultry feeds and natural occurrence of aflatoxin and zearelenone in the Rio de Janeiro State, Brazil. Mycopthology, 162, 335-362.

Park, J. W., Choi, S., Hwang, H., \& Kim, Y. (2005). Fungal mycoflora and mycotoxins in Korean polished rice destined for humans. International Journal of Food Microbiology, 103(3), 305-314. http://dx.doi.org/10.1016/j.ijfoodmicro.2005.02.001

Parker, I. M., \& Gilbert, G. S. (2004). The evolutionary ecology of novel plant-pathogen interactions. Annual Review in Ecological and Evolutionary Systematics, 35, 675-700. http://dx.doi.org/10.1146/annurev.ecolsys.34.011802.132339

Pitt, J. I., \& Hocking, A. D. (1997). Primary keys and miscellaneous fungi. In Fungi and Food Spoilage (2nd Ed., pp. 59-171). Blackie Academic and Professional. London, Weinheim, New York, Tokyo, Melbourne, Madras. http://dx.doi.org/10.1007/978-1-4615-6391-4_5

Politis, T., Fegeros, K., Nitsch, S., Schatzmayr, G., \& Kantas, D. (2005). Use of Trichosporon Mycotoxin ivorans to suppress the effects of ochratoxicosis on the immune system ofb roilcr chicks. Poultry Science, 46, 58-65. http://dx.doi.org/10.1080/00071660400023904

Pruthi, A. K., Batra, P., \& Sandana, J. R. (1992). Comparative studies on cell-mediated immune responses in herpesvirus of turkey vaccinated aflatoxin B1 fed and normally fed chickens. Proc World Poultry Congress, $19,15-20$.

Rippon, J. W. (1988). Medical mycology (2nd ed., pp. 640-641). Chicago Illinois, USA: W. B. Sanders company.

Rosa, C. A. R., Ribeiro, J. M. M., Fraga, M. J., Gatti, M., Cavaglieri, L. R., Magnoli, C. E., ... Lopez, C. W. G. (2006). Mycoflora of poultry feeds and ochratoxin-producing ability of isolated Aspergillus and Penicillium species. Veterinary Microbiology, 113, 89-96. http://dx.doi.org/10.1016/j.vetmic.2005.10.031

Singh, A., Oberoi, M. S., Jand, S. K., \& Singh, B. (1996). Epidemiology of inclusion body hepatitis in poultry in Northern India from 1990 to 1994. Rev. Sci. Teeh., 15, 1053-1060. 
Smith, J. E., \& Moss M. O. (1985). Mycotoxins: formation, analysis and significance (pp. 1-143). Chichester, Britain: John Wiley \& sons.

Smith, J. W., Prince W. R., \& Hamilton, P. B. (1969). Relationship of aflatoxicosis to Salmonella gallinarum infections of chickens. Applied Microbiology, 18, 946-947.

Smith, T. K., \& Seddon, I. R. (1998). Synergism demonstrated between Fusarium mycotoxins. Feedstuffs, 70, 12-17.

Somvanshi, R., \& Mohanty, G. C. (1991). Pathological studies on aflatoxicosis, infectious bursal disease and their interactions in chickens. Indian Journal of Pathology, 15, 10-16.

Wyatt, R. D., \& Hamilton, P. B. (1975). Interaction between aflatoxicosis and a natural infection of chickens with Salmonella. Applied Microbiology, 30, 870-872. 